\title{
Torcida familiar: a complexidade das inter-relações na iniciação esportiva ao futebol
}

\author{
Fabrício M. Filgueira \\ Gisele M. Schwartz
}

https://doi.org/10.5628/rpcd.07.02.245

\author{
LEL - Laboratório de Estudos do Lazer \\ $D E F / I B / U N E S P$ \\ Rio Claro $S P$ \\ Brasil
}

\section{RESUMO}

Este estudo, de carácter qualitativo, discutiu a efectividade das interacções pessoais e os aspectos intervenientes da torcida em relação à criança, na prática competitiva do futebol, em fase de iniciação esportiva. O estudo constou da união entre pesquisa bibliográfica e de campo, utilizando-se um questionário misto como instrumento para colecta dos dados. Esse instrumento foi aplicado a 20 crianças, do sexo masculino, matriculadas em uma escola especializada no ensino do futebol, com faixa etária entre 11 e 12 anos. Os dados foram analisados de forma descritiva, pela Técnica de Análise de Conteúdo Temático e identificam a grande participação dos pais na torcida, durante os jogos de futebol dessas crianças; a aceitação das crianças em relação à presença de seus pais nos jogos; os efeitos negativos da crítica da torcida; as influências da torcida sobre a forma de jogar das crianças e o papel importante do incentivo da torcida como fator motivacional. Com base nos resultados da pesquisa, sugere-se que novos estudos sejam elaborados, para implementarem a preparação psicológica de crianças nesta fase de aprendizado esportivo.

Palavras-chave: relacionamento interpessoal, iniciação esportiva, futebol, psicologia do esporte

\section{ABSTRACT \\ Parental support: inter-relationships complexity in football sportive initiation}

This study, with a qualitative trait, discussed the usefulness of personal interactions and the interventional aspects of cheerers in relation to children, in the competitive practice of soccer, when initiating in sports. The study consisted of an alliance between a bibliographic research and field research, using an assorted questionnaire as an instrument of data collection. This instrument was applied to 20 male children, between the ages of 11 and 12, enrolled in a specialized soccer school. The data were analyzed in a descriptive way by the Analysis Technique of Thematic Content and they identify a great participation of parents when cheering in these children's soccer matches; children's approval of their parents' presence in the games; the negative effects when the cheerers criticize, the cheerer's influence on the way these children play; and the important role of cheerers' incentive as a motivational factor. Basing on the research results, it is suggested that new studies should be elaborated to implement the children psychological preparation in this stage of sport learning.

Key-words: interpersonal relationship, sport initiation, soccer, sport psychology 


\section{INTRODUÇÃO}

Nas relações humanas, as influências interpessoais desenvolvem-se como um processo que envolve componentes como os modos de ser, de pensar, de sentir, de agir e de mudança de comportamento(11). Dentre as relações mais primárias encontra-se o complexo processo que é a relação entre pais e filhos, especialmente quando se focaliza directamente o âmbito da iniciação esportiva.

Tanto a criança como os pais possuem valores, atitudes, condutas e expectativas semelhantes, os quais são resultados da qualidade dessa interacção. Assim, compreender-se a qualidade do relacionamento interpessoal entre os envolvidos é de crucial importância no esporte, especialmente no que tange ao modo como os iniciantes percebem e interpretam a participação de seus pais durante a sua prática esportiva.

A psicologia do esporte tornou-se cada vez mais importante no desenvolvimento dos programas atléticos a fim de promover um desenvolvimento físico e psicológico saudável de iniciantes(16). Sendo estas as bases de sustentação para este estudo, a fim de entender melhor como os iniciantes recebem e se comportam, diante das atitudes e comportamentos da torcida durante os jogos, composta, nesta fase inicial, basicamente pelos pais, e os caminhos de influência directa na condução e orientação de acções que norteiam a qualidade desses relacionamentos entre os envolvidos, a fim de contribuir para a reflexão sobre as estratégias para minimizar seus efeitos negativos.

Um programa de treinamento projectado para ajudar técnicos nos esportes na juventude a relacionar-se mais eficazmente com seus jogadores ${ }^{(16)}$, onde a iniciação esportiva é um fenómeno humano absolutamente complexo, especialmente no que concerne aos aspectos envolvendo as interacções pessoais e ainda a presença da torcida.

Para tanto, cabe evidenciar as influências paternais sobre o processo linear de desenvolvimento e desempenho esportivo dos participantes iniciantes em uma modalidade esportiva.

O crescimento e o desenvolvimento da criança sofrem influências culturais, sociais e biológicas directa dos pais, desde os primeiros anos de vida. Especialmente quando se focaliza o aspecto esporti- vo, no caso o futebol, essas interferências são inequívocas, principalmente quando se trata de crianças do sexo masculino.

Em relação ao esporte infantil, verifica-se que a torcida é composta, em sua maioria, por pais(15), o que reforça a necessidade de se analisar a participação desses no contexto do futebol infantil, tanto no âmbito da aprendizagem, quanto no contexto competitivo.

A competição é alvo deste estudo, uma vez que pode gerar inúmeros efeitos sobre o comportamento das crianças, como atletas, nesses eventos. Além disso, pesquisas mostram que quanto mais jovem e menos experiente o atleta, maior será o efeito da torcida sobre seu comportamento( ${ }^{(7)}$.

$\mathrm{Na}$ literatura ainda são tímidos os estudos relacionados aos efeitos da torcida sobre o comportamento das crianças, uma vez que existem relatos de sentimentos positivos (competência, orgulho, motivação, etc.) e sentimentos negativos (fracasso, abatimento, etc.).

A presença dos pais nos treinos, nos jogos, ou em qualquer outro lugar vai despertar alguma reacção no atleta/criança, seja ela de contentamento ou constrangimento, de aprovação ou desaprovação(10). Segundo estudos da psicologia do esporte $(6,8,10)$ relata-se que algumas crianças podem se sentir incomodadas com a presença dos pais, enquanto outras se sentem bem com a presença dos familiares.

Portanto, o relacionamento que o atleta tem e teve com os pais, o modo como este atleta foi criado, as lembranças, os acontecimentos, os fatos que marcaram sua vida, tudo isto pode exercer influência directa sobre o atleta e seu modo de agir, do início da actividade física até o treinamento e a competição(10).

Algumas centenas de milhões de crianças estão envolvidas na prática de uma modalidade esportiva em todo o mundo(1).

No Brasil, o futebol é um fenómeno cultural que cativa e impressiona pela sua grandeza, e cuja prática tem crescido rapidamente, envolvendo um número significativo de participantes, desde a infância até a idade adulta.

Especificamente, na iniciação esportiva ao futebol, em um país como o Brasil, em que um único esporte 
merece a esmagadora atenção da mídia, é complicado mostrar às crianças que, muitas vezes, a escolha por esta modalidade esportiva é muito mais uma questão cultural do que um gosto pessoal. Até mesmo os pais são influenciados por isso, já que muitos pais, fanáticos por futebol, têm dificuldades em permitir que seus filhos optem por outro caminho para a prática esportiva.

Porém, o esporte na infância deve ser tratado de maneira adequada, respeitando-se a individualidade da criança, independente dos interesses ou objectivos das instituições formais ou informais.

O esporte deve se adaptar às condições técnica, física e psíquica da criança de forma compatível com suas necessidades e possibilidades, adequando-se à sua maturação orgânica funcional.

Um dos primeiros passos a serem dados é perguntar às crianças se é isso mesmo que elas querem, atendendo as suas próprias expectativas e necessidades, não às dos pais, técnicos, dirigentes ou de outros interesses alheios aos dos agentes principais: as crianças ${ }^{(5)}$.

Em fase de iniciação, a criança precisa aprender e conviver com o esporte, vivenciar diferentes situações, construir ideias e valores, descobrir sentimentos e incorporar transformações sociais, afectivas, intelectuais e motoras essenciais para a formação do carácter do indivíduo e para o seu futuro esportivo. Todo esse processo de transferência e formação ocorre de forma natural e envolve a genética e a interrelação social(6).

O sistema humano é considerado como grupo de pessoas que interagem com crianças, em função de fins e objectivos comuns, englobando essa interacção, inclusive, no esporte(14). Entre os principais protagonistas das relações interpessoais na fase de iniciação esportiva estão os familiares, os quais compõem o que se convencionou chamar de "torcida familiar". Este tipo de torcida está envolvida no complexo processo que é a relação entre os pais e as crianças no âmbito da iniciação esportiva ao futebol. Os pais são pessoas importantes, não apenas no cotidiano da criança, mas, de uma forma ou de outra, estão inseridos no processo de iniciação esportiva. Existe então, nesse contexto, uma relação dialéctica entre esses elementos:

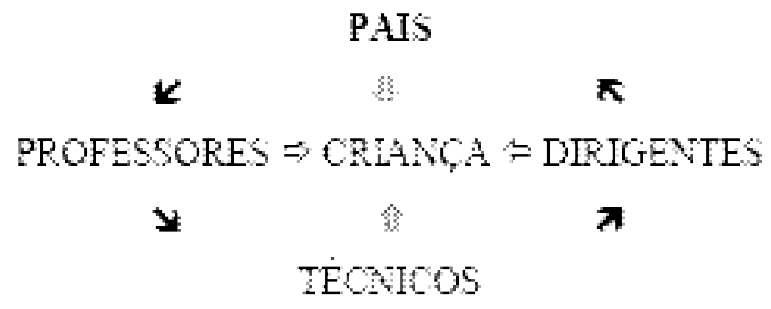

Muito mais que um simples aprendizado técnico, nesta complexa relação existe factores intervenientes que asseveram a necessidade de compreensão deste quadro, de maneira a perceber o envolvimento directo da criança neste processo.

Destarte, para melhor penetrar neste universo, esta pesquisa se restringe, apenas, a um determinado público, as crianças e pais, como familiares e torcedores inter-relacionados directamente com a formação esportiva, já que estes podem ter influência directamente no comportamento das crianças, em seus valores e atitudes e em suas relações.

As atitudes e condutas dos pais podem exercer reflexos e influenciar a participação da criança no esporte, inclusive nos campos de futebol.

A esse respeito, Machado(10) evidencia que a interacção da criança na sociedade sofre influências, em primeira instância dos pais, depois, ao iniciar a vida escolar, sofre influências dos professores e de outros grupos, como por exemplo, de uma equipe esportiva. A partir dessas inter-relações, a criança vai construindo sua subjectividade e moldando suas condutas, daí advindo a necessidade de análises aprofundadas sobre as influências destes segmentos e, mais especificamente, da torcida, procurando investigar sobre como as crianças recebem e se comportam diante da "torcida familiar", dentro da prática esportiva do futebol.

Segundo Filgueira (3) os professores, os técnicos, os pais e os dirigentes esportivos estão mais preocupados com seus anseios e pensando na sua satisfação em ver a criança jogar, ser titular, ser melhor que os outros, em vencer, ser campeão, do que com o próprio aprendizado daí advindo.

Em estudos realizados por Smith e Smoll(16) foram encontrados que os resultados os mais positivos ocorreram quando as crianças jogaram para os técni- 
cos que acoplaram em níveis elevados do reforço positivo para o desempenho desejável e o esforço, e ainda que respondessem aos erros com incentivo e instrução técnica, e que enfatizaram a importância do divertimento e da melhoria pessoal excedente a acção de vencer.

Exactamente esta satisfação pessoal dos técnicos e não a satisfação e prazer da criança é que gera inúmeros conflitos, fazendo desta um instrumento de autopromoção ou vaidade.

A torcida familiar, que está presente no âmbito do processo de formação esportiva no futebol, passa a ser aceita como um possível e importante factor de influência sobre atitudes e comportamentos das crianças envolvidas nesse processo.

Neste texto, pretende-se identificar o significado da presença dos pais e da torcida familiar para as crianças, durante os jogos, evidenciando como elas consideram esta participação da torcida e as influências de suas atitudes e comportamentos sobre a forma de jogar das crianças envolvidas, a fim de compreender melhor o envolvimento das inter-relações neste processo, no âmbito da iniciação esportiva ao futebol. Para tanto, foi desenvolvida a pesquisa exploratória, no sentido de se penetrar neste universo.

\section{METODOLOGIA}

Este estudo está restrito à análise qualitativa referente aos dados colectados, adequando-os ao contexto das inter-relações entre os alunos-atletas "mirins" e a torcida.

A pesquisa qualitativa adequa-se a esta finalidade, tendo em vista suas características e seu poder de penetração no âmago dos fenómenos sociais, conforme salienta Richardson ${ }^{(12)}$.

O estudo foi realizado com base em duas etapas complementares, sendo a primeira referente a uma pesquisa bibliográfica, sobre as temáticas em foco e a segunda relativa a uma pesquisa exploratória, utilizando-se como instrumento para a colecta de dados um questionário misto.

Também segundo apregoa Richardson(12), esta técnica permite maior facilidade de apreensão dos resultados, tendo em vista que este tipo de questões favorece a fluência e a participação efectiva dos participantes. O estudo foi desenvolvido utilizando-se como instrumento para colecta de dados um questionário conten- do perguntas mistas, as quais se caracterizam em abertas, fechadas e/ou de múltipla escolha. As questões mistas ampliam e enriquecem a maneira de participação do sujeito, adequando-se ao tipo de pesquisa proposta no estudo.

Ruiz(13), assim como Filho e Santos(4) consideram o questionário misto favorável para a colecta de informações desta natureza, pelo fato de questões deste tipo seguirem uma linha menos rígida ou fechada, ampliando

a perspectiva de respostas mais directas dos sujeitos e fomentando dados

mais aprofundados. Uma outra justificativa para a utilização do questionário misto para este estudo recai na perspectiva de que o entrevistado pode expressar suas colocações de forma mais espontânea e livre durante a colecta dos dados.

O instrumento foi composto por cinco questões mistas, ressaltando-se os factores de relações interpessoais e foi aplicado a uma amostra intencional, composta por vinte alunos-atletas participantes, de sexo masculino, iniciantes de futebol, na faixa etária entre 11 e 12 anos, de uma escola especializada de futebol, a Escola de Futebol Oficial do São Paulo Futebol Clube, da cidade de Ribeirão Preto-SP, sendo que os alunos-atletas realizam treinamentos de uma hora e meia, duas vezes por semana.

O questionário foi aplicado, com a autorização do técnico da categoria, antes dos treinamentos, no local onde os mesmos estavam sendo realizados. As instruções para preencher o questionário foram comentadas, como também, as dúvidas dos alunosatletas foram esclarecidas antes de se iniciar as respostas em forma de questões abertas.

Os dados obtidos por meio do instrumento proposto foram analisados descritivamente, por meio da utilização da técnica de Análise de Conteúdo Temático, a qual(12) permite obter, diretamente, a informação relativa ao tema da pesquisa, eliminando-se outras possíveis variáveis intervenientes.

Deste modo, para facilitar a análise das respostas, foram formulados indicadores, os quais congregavam a incidência de elementos comuns entre as respostas dos participantes.

Esses indicadores levaram em consideração as pessoas que mais assistem aos jogos; a reacção dos atletas sobre a presença dos pais nos jogos; os senti- 
mentos dos atletas perante a crítica da torcida; as influências da torcida na sua forma de jogar e, finalmente, os aspectos motivacionais resultantes do incentivo da torcida.

\section{RESULTADOS E DISCUSSÃO}

As ordens de apresentação dos resultados encontram-se, respectivamente, na forma das respostas comuns relacionadas aos factores acima mencionados. Cada resposta é agrupada em indicadores comuns relatados pelos atletas e exemplificados a partir da pergunta a que pertence (Quadro 1). Os relatos apontam a presença dos pais como um factor importante, pois são os integrantes da família que mais assistem aos jogos de futebol, conforme resposta à questão 1 .

$\mathrm{O}$ crescimento e o desenvolvimento da criança sofrem influência directa dos pais, independente de qual sociedade se insere a família(10). Esta relação pais-crianças é bastante evidente no esporte, especialmente em fase inicial, o que se confirmou com o resultado deste estudo.

Entretanto, esta presença dos pais que acompanham os filhos na prática esportiva pode gerar problemas de efeitos positivos, neutros ou negativos em treinamentos e competições.

Quadro I. Respostas dos atletas.

\begin{tabular}{|c|c|}
\hline Resposta à questão1: & Meu Pai (14] \\
\hline \multirow[t]{2}{*}{ Quem assiste mais aos seus jogos de futebol? } & Meus Pais [3] \\
\hline & Meu Técnico (3) \\
\hline Resposta à questão 2: & Sim (17): incentivam; motivam; jogar melhor. \\
\hline Você gosta que seus pais assistam aos seus jogos de futebol? Por quê? & Não (3): gritando; falando muito. \\
\hline Resposta à questão 3: & Mal (18): "me sinto mal" \\
\hline \multirow[t]{2}{*}{ Como você se sente quando a torcida o critica? } & Triste (1) \\
\hline & Com mais responsabilidade (1] \\
\hline Resposta à questão 4: & Sim (9):"posso melhorar" \\
\hline \multirow[t]{9}{*}{ Você acha que a torcida pode influenciar sua forma de jogar? Explique. } & Sim (2):"fico abatido" \\
\hline & Não (9): \\
\hline & "não dou atenção para torcida"[2] \\
\hline & "não dou ouvido"[2] \\
\hline & "não ligo para o que as pessoas falam de mim"(1) \\
\hline & "falam mal das pessoas"(1) \\
\hline & “eles só atrapalham"[1] \\
\hline & "jogo do meu jeito"(1) \\
\hline & "ignoro a torcida"(1) \\
\hline Resposta à questão 5: & $\operatorname{Sim}(17):$ \\
\hline \multirow[t]{10}{*}{ Você se motiva mais com o incentivo da torcida? Explique. } & "jogar melhor"(4) \\
\hline & "é um incentivo"(3) \\
\hline & "não estou jogando mal"(2) \\
\hline & "torce para mim"[2] \\
\hline & "motivado" (2) \\
\hline & "me sinto mais a vontade"(1] \\
\hline & "ajuda dentro de campo"(1) \\
\hline & “não esta tudo perdido"(1) \\
\hline & "dão força"(1) \\
\hline & Não (3): "não escuto" \\
\hline
\end{tabular}


Segundo Cratty(2), o atleta nunca deixa de sofrer influência de alguma assistência, em qualquer etapa de seu envolvimento esportivo.

Os pais sempre estarão interagindo ou interferindo com a criança em sua vida e, quando estes fazem parte da torcida, há a influência sobre o desempenho do atleta. Vale ressaltar que outros elementos são também intervenientes nesse processo, como a idade, a experiência e a importância do jogo, os quais representam factores que podem agravar ou aprimorar o desempenho do atleta.

Deste modo, a reacção da criança perante a presença dos pais em seus jogos dependerá da maneira como esta foi educada, do tipo de sua personalidade e, ainda, das ressonâncias das experiências anteriormente vivenciadas.

Segundo alguns estudos $(8,9)$ existem crianças que se sentem incomodadas com a presença dos pais, enquanto algumas se sentem bem, podendo haver, inclusive, uma melhoria em seu desempenho. Tudo vai depender da qualidade do relacionamento entre pais e filhos, influenciando directamente na maneira da criança agir durante o treinamento e a competição. Quando um pai faz um comentário durante uma competição, sua intenção, na maioria das vezes, é motivar o filho e conduzi-lo a um desempenho mais adequado ou à vitória; no entanto, nem sempre a forma empregada para fazê-lo é a mais adequada(15). Em se tratando do processo de iniciação esportiva, pode-se constatar que a torcida, na sua maioria, é composta pelos pais. Os pais são um dos elementos do grupo de pessoas que acompanham e interagem com a criança na iniciação esportiva e como agentes envolvidos influenciam directamente no seu desenvolvimento.

De acordo com os relatos, resposta 2 , as crianças se sentem motivadas e incentivas, favorecendo, desta maneira, um melhor desempenho. Porém, em alguns casos, as crianças se sentiram incomodadas, em virtude dos gritos dos pais.

A actuação da torcida poderá ser um factor que altera a performance do atleta ou atinja o atleta de alguma maneira ${ }^{(10)}$.

Nesta questão, as respostas demonstram a presença dos pais durante os jogos de futebol com efeitos positivos para o desempenho das crianças, como forma de incentivo, motivação ou como influência para jogar melhor, resultados que corroboram com o estudo realizado por Isler ${ }^{(6)}$, no qual o autor aponta a presença dos pais nos jogos como um fato importante para o desempenho positivo ou o bem-estar do filho.

Os relatos evidenciaram a significância da presença dos pais como um factor que altera o desempenho da criança para níveis melhores de desempenho. Ter uma experiência mais positiva com o esporte é importante ${ }^{(15)}$, visto que a prática de uma actividade física bem conduzida propicia melhoria da condição nos níveis físicos e motor, aprimorando a auto-imagem e a autoconfiança e contribuindo para uma vida mais saudável.

Ao contrário, alguns relatos caminham para o desconforto mediante acções por meio de gritos e verbalizações constrangedoras para as crianças.

Sobre a presença dos pais, Filgueira( ${ }^{(3)}$ salienta que estes deveriam passar tranquilidade aos filhos e se divertirem, o que, geralmente, não acontece, já que ficam nervosos, gritam, criticam e alguns são, inclusive, violentos.

O fato é que, com base nos resultados do estudo, pode-se afirmar que, para algumas crianças, a presença dos pais é importante para o seu desenvolvimento no processo ensino-aprendizagem-treinamento, contrariando alguns posicionamentos de senso comum, de que seria melhor se os pais não estivessem presentes durante as actividades esportivas das crianças, para se evitar esses constrangimentos acima relatados.

$\mathrm{Na}$ resposta 3, as crianças demonstram, de forma bem clara, suas reacções perante a crítica. As criticas transmitidas pela torcida, muitas vezes vindas de pais autoritários, geram influências negativas sobre o comportamento das crianças.

Referenciado por diferentes autores ${ }^{(10)}$, a proximidade do público, a maneira como o atleta o encara e como recebe os elogios e as criticas, vai influenciar sua conduta no jogo e suas reacções frente à torcida. De certa forma, os pais acreditam que as críticas podem melhorar o desempenho da criança durante a competição, no entanto, se forem feitas de maneira agressiva ou em forma de cobranças violentas, ao contrário, podem alterar negativamente a sua autoimagem, implementando sentimentos de inferioridade e de medo do fracasso. 
A criança pode gerar um sentimento de que não é competente o suficiente, desistindo de tentar ou esquivando-se de situações nas quais possa ser avaliada negativamente e criticada(15).

Os pais devem entender que as criticas, muitas vezes, ao invés de ajudarem, acabam atrapalhando. Nas melhores das intenções, os pais querem tanto ajudar e fazer com que seus filhos tenham um bom desempenho, que se esquecem que não depende apenas deles, e sim, muito mais dos próprios filhos se tornarem bons jogadores.

Deste mesmo modo(6), a maneira como o atleta encara o público, como ele o valoriza ou como recebe as críticas são factores que influenciam seu desempenho e suas reacções diante dos torcedores. De uma forma bem clara: ser deselegante com outros pais, com seus filhos, com a arbitragem, supervalorizar a vitória ou a derrota da criança, são equívocos e tendem a atrapalhar, não só a criança, mas também o meio esportivo(14).

Vale ressaltar que a escolha pela prática de uma actividade esportiva pelos filhos se deve muito ao ambiente social vivido pela família. A família tem papel primordial no envolvimento das crianças com o esporte, reproduzindo suas características culturais económicas como factores do ambiente físico e emocional, atitudinal e de condutas dos filhos, durante a prática de actividades esportivas.

Para Isler(6), a presença da família, como de toda a torcida, inibe ou estimula a actuação da criança, dependendo do nível de habilidade em que se encontra. O potencial de avaliação de uma torcida é um dos factores mais importantes que se acredita existirem como modificador do desempenho do atleta, segundo estudos realizados por Cratty(2).

Não procede haver tantas criticas na maneira de jogar da criança, tendo a preocupação imediata com o desempenho. Exactamente nessa inter-relação começam a surgir questões passíveis de questionamentos, como o efeito do comportamento dos pais, e, também dos outros elementos como: técnicos, dirigentes, organizadores, árbitros, já que, muitas vezes, as críticas são destrutivas e não são posicionadas em momento adequado, para servirem, talvez, como incentivo a mudanças.

Para algumas crianças, a torcida exerce uma influência positiva para o seu desempenho, enquanto para outras essa influência não é percebida ou é prejudicial a sua forma de jogar, conforme relatos da resposta 4. A torcida, através de seus artifícios, certamente actuará sobre o desempenho do atleta de alguma maneira sendo que a experiência de vida, a idade e personalidade são variáveis importantes no desempenho da criança iniciante.

$\mathrm{O}$ relacionamento que o atleta tem e teve com os pais, o modo como ele foi criado, as lembranças, os acontecimentos, os fatos que marcaram sua vida, tudo isto vai influenciar o atleta e seu modo de agir, do início da actividade física até o treinamento e a competição(10).

Ainda segundo o autor, consequentemente, cada um vai reagir ou agir de formas diferentes a mesma situação. A questão é que nem todos estão conscientes disto, bem como, do risco que isto provoca. Neste contexto, o professor, o técnico ou a torcida familiar são pessoas inconscientes de seus deveres e responsabilidades sobre suas atitudes e comportamentos, para que não se tornem exigentes demais, a ponto de estragarem o prazer da criança em jogar futebol, ou, o que é mais trágico, interferirem na possibilidade de esta criança ter aversão ao esporte, entrando em um processo sedentário.

Conforme o resultado do estudo, a torcida pode influenciar ou não a forma de jogar e o desempenho da criança durante a partida, uma vez que as respostas foram muito próximas, sendo 11 afirmativas contra 9 negativas. Esta comparação é importante porque evidencia a presença de outras variáveis, as quais dizem respeito a que, dependendo da personalidade do aluno-atleta, a torcida pode representar, tanto estímulo positivo como negativo para a criança em seu desempenho.

Ao contrário, em relação ao incentivo, este indubitavelmente é extremamente necessário aos iniciantes futebolistas, uma vez que os tornam mais motivados, modificando ou influenciando seu comportamento e desempenho durante a prática esportiva, conforme observado nas respostas 5.

Para os autores ${ }^{(10)}$, o incentivo pode tomar a forma de um impulso interno para o sucesso, para provar ou conseguir algo para se auto-realizar.

Nestes casos, os incentivos se tornam efeitos de motivação positivos, potencializando o desempenho do indivíduo, tornando-se um apoio à aquisição de segurança e um estado motivacional que o desperta para jogar melhor. 
Sobre os elogios e incentivos(15), os autores complementam que, com comentários de natureza positiva, os pais mostram que valorizam o que a criança faz de bom. Por sua vez, as crianças se sentem mais valorizadas, seguras e competentes.

No entanto, os mesmos autores $(15,3)$ comentam sobre alguns cuidados necessários para utilização dos recursos que incentivam como os elogios, palavras de apoio, sinceridade e encorajamento, são eles: 1 - Descontrair a criança antes da competição;

2 - Evitar críticas e ofensas durante a competição;

3 - Não exceder na quantidade de instruções;

4 - Não depreciar outras crianças ou equipes;

5 - Valorizar as acções positivas com sinceridade.

Sobre a presença da família, como de toda a torcida ${ }^{(6)}$, o efeito da inibição ou estimulação será proporcional à importância que a torcida tem na vida do atleta.

O mesmo autor defende que, considerando-se o papel fundamental da família na vida da criança, quanto maior apoio familiar, maior será o empenho da criança dentro da actividade.

Sendo assim, quando uma criança, além de ser motivada extrinsecamente pelos pais ou pela torcida, de modo geral, torna-se extrinsecamente motivada para o futebol, ela o faz pelo simples prazer e satisfação obtidos pela prática da actividade, tendo neste bojo todos os factores anteriormente apontados, como elementos capazes de gerar, não só a aderência ao esporte, mas a forma consciente de introjeção no mesmo.

A torcida pode ser um factor de cobranças e exigências, mas, aparentemente, conforme os dados obtidos pelos instrumentos aplicados, os alunos-atletas se sentem motivados por esta forma de pressão social no esporte.

\section{CONSIDERAÇÕES FINAIS}

Os dados decorrentes deste estudo evidenciam alguns indicadores importantes das inter-relações entre torcida e atletas iniciantes, como a importância do papel do pai na relação da criança com o futebol; a dinamização propiciada pela presença dos pais nos jogos, tornando-se um factor de motivação para criança; os aspectos negativos causados pela crítica da torcida, em que os iniciantes se sentem mal quando recebem a desaprovação da torcida; e, por fim, o incentivo da torcida como sendo um recurso motivacional positivo para a actuação da criança. As atitudes e comportamentos das crianças futebolistas recorrentes das interferências da torcida durante os jogos são efectivamente influenciadas, com base nos diversos níveis de interpretação pessoal, o que tem directa relação com as vivências anteriores de uma criança, assim como, com seu enredo psicológico.

Como sugestões advindas com base nos resultados desta pesquisa, têm-se a importância de o técnico, assim com o professor envolvido no processo de acompanhamento das crianças iniciantes no esporte, promover encontros e reuniões periódicas com os pais e com os próprios alunos-atletas, evidenciando todas estas questões que permearam as discussões neste estudo.

De igual importância são as preparações psicológica e pedagógica do professor ou técnico, para lidar com os estados subjectivos que envolvem a dinâmica da prática profissional, salientando estas temáticas nos cursos de formação nas Ciências da Motricidade, além da necessidade de se implementar a leitura de bibliografia actualizada.

Os resultados apontam para uma relação mais harmoniosa entre os alunos-atletas e os pais e a compreensão por parte desses de que o esporte praticado pelas crianças, no caso o futebol, têm sua finalidade na socialização, e ainda, a torcida, composta na maioria pelos pais, tem papel extremamente importante para que, cada vez mais, se possa interagir com a criança de maneira saudável.

Os pais que convivem com ela diariamente e a acompanham no esporte influenciam directamente, assim como os professores e técnicos e outros elementos, especialmente àquelas crianças mais sensíveis e com personalidade mais vulnerável a criticas.

À medida que todos os elementos envolvidos puderem interagir de forma mais positiva e equilibrada, pensando, não apenas no momento do afã do jogo, mas sim, na possibilidade de concretização de objectivos educacionais, acompanhando e apoiando as crianças, estes poderão efectivamente fazer a diferença, investindo em uma formação mais autónoma e motivada, impelindo-as a incorporarem o esporte em suas vidas de maneira prazerosa e por opção própria, transformando a simples experiência corporal, na perspectiva de assimilação de valores existenciais qualitativos. 
Torna-se importante a elaboração de novos estudos, capazes de levar em consideração a pedagogia do esporte, bem como a psicologia do esporte, envolvendo a iniciação esportiva do futebol em suas relações com uma rede de evidências de complexidades, as quais devem ser melhor discutidas, tendo em vista a decisiva e directa influência no que concernem às relações interpessoais pertinentes ao esporte e, especificamente, à formação esportiva da criança, em fase inicial.

\section{REFERÊNCIAS BIBLIOGRÁFICAS}

1. Becker BJ, Teloken E (2000). A Criança no Esporte. In: Becker BJ. Manual de Psicologia do Esporte \& Exercício. Porto Alegre: Ed. Nova Prova, p. 131-156.

2. Cratty BJ (1984). Psicologia no esporte. Rio de Janeiro: Prentice-Hall do Brasil.

3. Filgueira FM (2004). Futebol: uma visão da iniciação esportiva. Ribeirão Preto: Ribergráfica.

4. Filho DP, Santos JA (2001). Metodologia científica. São Paulo: Futura.

5. Frisselli A (1994). Cuidado: Futsal Menores. Boletim Técnico Científico (APEF), Londrina, ano 3, n. 3, jul.

6. Isler GL. (2003). Atleta, como seus pais o motivaram para a prática esportiva? Análise das histórias de vida. $113 \mathrm{f}$. Dissertação (Mestrado em Ciências da Motricidade) Instituto de Biociências, Universidade Estadual Paulista, Rio Claro.

7. Lord RH, Kozar B (1989). Pain tolerance in the presence of others: implications for youth sports. Physician and Sportsmedicine, 17: 71-77.

8. Machado AA (1996). Ansiedade e Agressividade no Espetáculo Esportivo. Rio Claro: UNESP (Relatório de Pesquisa).

9. Machado AA (1994). Aspectos psico-pedagógicos da competição esportiva escolar. Tese (Doutorado em Educação) Faculdade de Educação Física, Universidade Estadual de Campinas, Campinas.

10. Machado AA, Miotto AM, Presoto D, Santos RVT (1997). O momento esportivo e uma forte influência externa: a torcida. In: Buriti, M de A (Org.). Psicologia do Esporte Coleção Psicotemas. Campinas: Editora Alínea, p. 113-122.

11. Minicucci A (2001). Relações Humanas: psicologia das relações interpessoais. 6. ed. São Paulo: Atlas.

12. Richardson RJ (1989). Pesquisa social: métodos e técnicas. São Paulo: Atlas.

13. Ruiz JA (1996). Metodologia Científica: guia para a eficiência nos estudos. São Paulo: Atlas.

14. Santana WC (1996). Futsal: metodologia da participação. Londrina: Lido.

15. Silva MKPVFP, Souza SR (2003). A participação dos pais em eventos competitivos infantis: Algumas Orientaçốes. Londrina: Pedagogia do Futsal. Desenvolvido por Wilton Carlos de Santana. Disponível em: $<h t t p: / / w w w . p e d a g o g i a d o f u t s a l . c o m . b r / o u t r a s$ palavra $>$. Acesso em: 28 mai.

16. Smith RE, Smoll FL (1997). Coaching the Coaches: youth sports as a scientific and applied behavioral setting. Current Directions in Psychological Science 6(1): 16-21.

\section{CORRESPONDÊNCIA}

\section{Fabrício Moreira Filgueira}

Rua Dr. João Palma Travassos, 576 apt. 42

Jardim Macedo - Ribeirão Preto/SP

Cep: 14.091-18

e-mail: fmfmoreira@terra.com.br 